\title{
Projecto e construção de um goniómetro de angulos de contacto
}

MA D A L E A DIONÍSIO*a), JOAQUIM GARCIA b),

MARGARIDA MONTEIRO c), PEDRO RODRIGUES c),

J O Ã O S O T O M A Y O R *a)

(EM MEMORIA DE JOAQUIM GARCIA)

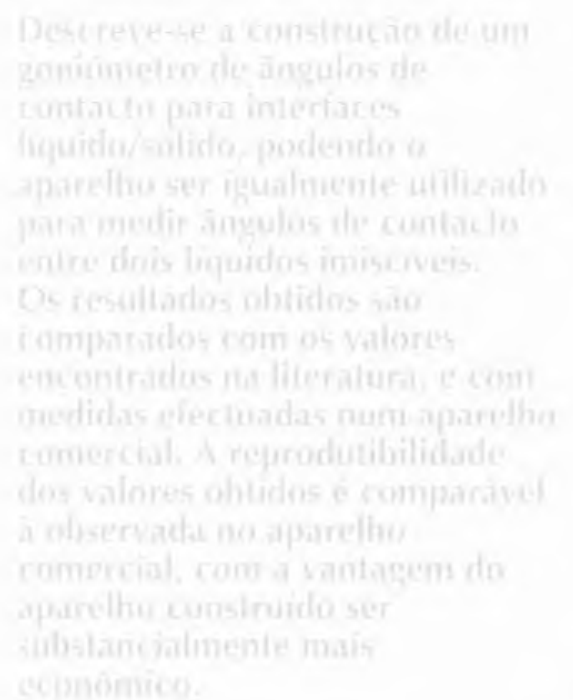

\section{1 - INTRODUÇÃo}

O interesse do estudo de fenómenos de superfície como molhabilidade e adesão, tem sido alargado a diferentes áreas da Ciência, nomeadamente à Ciência de Materiais e Ciência de Superfícies, sendo de grande importância no que respeita a aplicações tecnológicas. Assim, a compreensão de fenómenos daquele tipo pode resultar em que propriedades como a aderência ou hidro-repelência em tintas e tecidos ${ }^{1}$, a detergência em tensioactivos ${ }^{2}$, a compatibilidade em biomateriais ${ }^{3}$, e ainda as características topológicas de uma superfície sólida ${ }^{4}$, sejam modeladas e optimizadas.

A par da evolução da Ciência de Superfícies, surge o desenvolvimento de técnicas espectroscópicas, em paralelo com técnicas de ultra altovácuo, cada vez mais sofisticadas. Neste universo de tecnologia tão específica, a medida de ângulos de contacto surge com um método analítico relativamente simples, aliando o seu interesse na determinação de propriedades fundamentais, como a tensão superficial, à sua componente pedagógica.

Quando uma gota de líquido é depositada sobre uma superfície sólida, a forma que adopta resulta do efeito simultâneo de três forças: a tensão superficial da interface sólidovapor, $\gamma_{\mathrm{Sv}}$, a tensão superficial da interface líquido-vapor, $\gamma_{L V}$, e a tensão superficial da interface sólido-líquido, $\gamma_{\mathrm{SL}}$, definindo-se, ângulo de contacto, $\theta$,



Fig. 1 - Balanço de forças numa gota de líquido sobre a superfície de um sólido.

(ver Fig. 1), como o ângulo entre a superfície sólida e a tangente à superfície da gota no ponto de contacto desta com o sólido (ângulo entre $\gamma_{\mathrm{SL}}$ e $\gamma_{L V}$ ). Assim, quando um líquido é colocado sobre uma superfície sólida assumindo forma de gota, o seu ângulo de contacto com a superfície relaciona-se com aquelas tensões através da equação de Young ${ }^{\star *}$ :

$$
\gamma_{\mathrm{SV}}-\gamma_{\mathrm{SL}}=\gamma_{\mathrm{LV}} \cos \theta
$$

onde $\theta$ pode variar entre 0 e $180^{\circ}$. $\mathrm{O}$ lado esquerdo desta equação é um parâmetro de adesão, que descreve a tendência de um líquido para se espalhar sobre a superfície do sólido, isto é, a molhabilidade. Um líquido molha completamente o sólido se $\theta$ $=0^{\circ}$, ou parcialmente se $0^{\circ}<\theta<90^{\circ}$

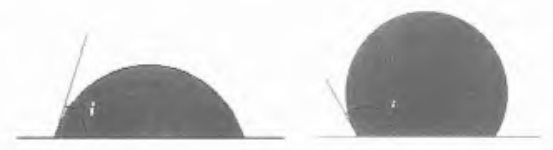

Fig. 2 - Líquidos com diferentes molhabilidades: a) o líquido molha parcialmente a superfície, $0^{\circ}<\theta<90^{\circ}$ b) o líquido não molha a superfície, $\theta>90^{\circ}$.

(exemplo: benzeno sobre teflon, $\theta=$ $46^{\circ} 7$, ver Figura 2a)). Líquidos cujos ângulos de contacto são superiores a $90^{\circ}$ diz-se que não molham a superfície sólida (exemplo: mercúrio sobre teflon, $\theta=150^{\circ} 7$, ver figura $2 \mathrm{~b}$ )).
Um ângulo de contacto de $180^{\circ}$ corresponde a uma situação ideal em que o líquido não molha o sólido.

Dupré define trabalho de adesão, $\mathrm{W}_{\mathrm{SL}}$, para a interface sólido-líquido como o trabalho necessário para separar uma unidade de área da interface sólido-líquido em duas interfaces sólido-vapor e líquidovapor, sendo dado por:

$$
\mathrm{W}_{\mathrm{SL}}=\gamma_{\mathrm{SV}}+\gamma_{\mathrm{LV}}-\gamma_{\mathrm{SL}}
$$

A equação (2) é designada por equação de Young - Dupré. O trabalho de adesão, atendendo à equação (1), pode ser igualmente dado por $^{* * *}$ :

$$
\mathrm{W}_{\mathrm{SL}}=\gamma_{\mathrm{LV}}(1+\cos \theta)
$$

Assim, conhecendo a tensão superficial do líquido e medindo o ângulo de contacto entre uma gota de líquido e a superfície sólida, é possível determinar o trabalho de adesão para a interface líquido-sólido e que será tanto maior quanto maior a molhabilidade, isto é, maior a afinidade do líquido para a superfície. Quando o líquido possui forças coesivas fortes, caso do mercúrio, tem pouca afinidade para a superfície (ex. vidro) e o trabalho de adesão ou, visto de outra forma, o trabalho para o separar do sólido, é menor.

Como foi referido, a técnica de determinação de ângulos de contacto não requer instrumentação muito complexa. A relativa facilidade de manuseamento, aliada à componente pedagógica deste tipo de medidas, torna a técnica de medidas de ângulo de contacto um apoio experimental ideal, nomeadamente para estudantes de licenciatura.

No presente artigo descreve-se um goniómetro de ângulos de contacto, construído por um de nós (J. Garcia), que conduz a resultados comparáveis aos de um goniómetro comercial (p.e, da firma Ramé-Hart), sendo consideravelmente mais económico. 


\section{2 - DESCRIÇÃO DO APARELHO}

O goniómetro utilizado neste trabalho foi construído de raiz, sendo constituído pelos seguintes componentes: base, microscópio, retículos para medição de ângulos, plataforma para suporte do porta amostras e sistema de iluminação do porta amostras. A Figura 3 mostra o aparelho construído e identifica algumas das suas partes mais importantes.

\section{Base on estativo}

A base é uma peça em forma de $\mathrm{T}$ construída em perfil de alumínio, tendo nas suas extremidades parafusos que permitem proceder ao seu nivelamento.

\section{Microscópio}

Sobre a base encontra-se solidamente aparafusada a parte do instrumento destinada a poder proporcionar a observação microscópica da gota. Este componente é constituído por elementos mecânicos e ópticos que passamos a descrever:

\section{Elementos mecânicos}

Uma estrutura prismática truncada é encimada por um tubo desti- nado a receber a ocular do microscópio (1 da Fig.3). Essa estrutura é composta por duas partes que deslizam entre si por meio de um dispositivo mecânico que permite o ajuste de focagem (2 da Fig.3) dos elementos ópticos. A parte superior da estrutura é oca, destinada a receber um espelho e a servir de suporte à objectiva do microscópio (3 da Fig.3).

\section{Elementos ópticos}

A objectiva está montada horizontalmente, para que se possa observar o perfil da gota. À objectiva segue-se um espelho plano (espelhagem à face), o qual permite desviar o trajecto do feixe óptico numa direcção tal, que a ocular se apresente para o observador numa posição confortável.

A escolha desta combinação de elementos ópticos teve em vista a possibilidade de observar a gota com a concavidade virada para cima, apresentando sómente uma inversão direita esquerda do bordo, sem qualquer inconveniente para a observação. É assim muito mais agradável e intuitivo visualizar uma imagem em posição direita e não invertida, como em alguns instrumentos comercializados.

Optou-se por elementos ópticos

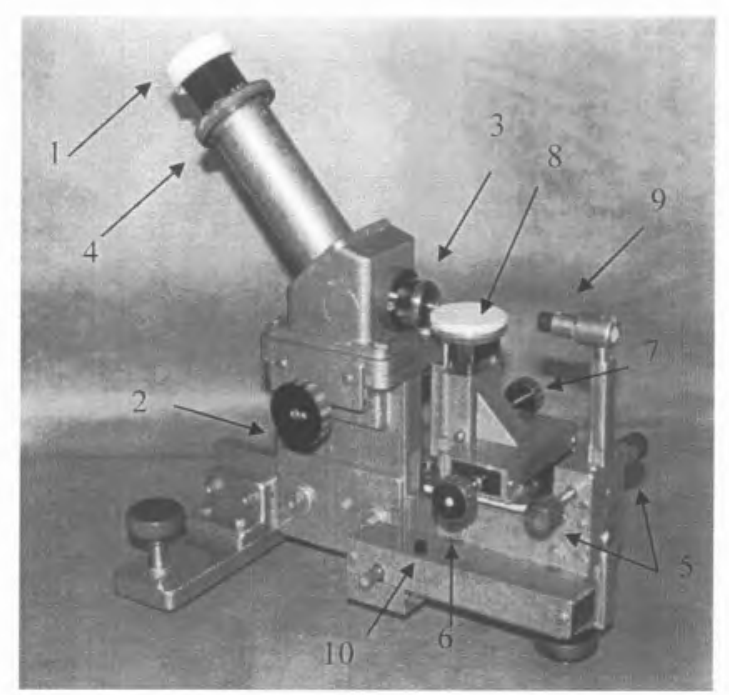

LEGENDA:

1- Ocular

2- Focagem

3- Objectiva

4- Anel de ajuste do reticulo em cruz

5- Focagem fina ou deslocamento longitudinal

6- Deslocamento transversal

7- Deslocamento vertical

8- Porta amostras

9- Sistema de iluminação

10- Interruptor do LED com as seguintes características: uma objectiva de $40 \mathrm{~mm}(4 \mathrm{X})$ e f:0.1, e uma ocular de $20 \mathrm{~mm}$ (12.5X), o que perfaz um valor de ampliação do microscópio de 50 aumentos (50X). permitindo uma distância de trabalho de $37 \mathrm{~mm}$.

A objectiva é um simples doublet acromático. A ocular é uma kellner com uma lente de olho acromática e uma lente de campo simples. A ocular foi mecanicamente modificada a fim de poder comportar no seu plano focal um dos retículos (retículo em cruz), que tem movimento rotativo para poder proporcionar a leitura dos ângulos (4 da Fig.3).

O segundo retículo, graduado de 0 a $360^{\circ}$, é fixo. Encontra-se montado no interior do tubo do microscópio e justaposto ao primeiro retículo à distância de $0.05 \mathrm{~mm}$, de modo a obter-se focagem para o conjunto.

\section{Plataforma para suporte do porta-amostras}

Três estruturas paralelipipédicas sobrepõem-se ortogonalmente e estão entre si justapostas por meio de calhas que lhes permitem movimentos longitudinal, transversal e vertical em relação à base do instrumento.

A primeira das estruturas a contar da base está sólidamente aparafusada nesta, e tem no seu interior um dispositivo para deslocamento longitudinal de todo o conjunto ( 5 da Fig.3). Trata-se de um sistema mecânico constituído por um parafuso de passo fino ( 2 espiras $/ \mathrm{mm}$ ), accionado por uma roda dentada e senfim, proporcionando um factor de desmultiplicação de 10X. Desta forma dispõese de um movimento micrométrico de movimentação lenta, que permite focagens de grande precisão.

Justaposta a esta primeira estrutura e solidária com ela, encontra-se uma segunda que apresenta um dispositivo de deslocamento segundo um eixo transversal. Este movimento é obtido por rotação de um parafuso, que não apresenta desmultiplicação a fim de se conseguir um movimento rápido (6 da Fig.3). 
Uma terceira estrutura solidária com as anteriores, é montada de forma a proporcionar movimento segundo um eixo vertical (7 da Fig.3). Na parte superior encontra-se uma plataforma circular de $25 \mathrm{~mm}$ de diâmetro, destinada a receber o porta amostras (8 da Fig.3). Foram construídos vários porta amostras em 4 materiais diferentes: teflon - politetrafluoroetileno (PTFE), poli (cloreto de vinilo) (PVC), aço inox e vidro. Desta forma é possível medir ângulos de contacto sobre diferentes substratos sólidos.

\section{Sistema de iluminação}

É constituído por uma estrutura tubular ortogonal através da qual passam os fios eléctricos destinados a fornecer corrente a um LED de alta intensidade luminosa (9 da Fig.3). Este sistema possibilita a movimentação do LED quer na direcção vertical quer em rotação, permitindo regular adequadamente a iluminação da gota. A fonte de alimentação é proporcionada por duas pilhas alcalinas de 1.5 Volt.

O circuito de alimentação consta de: um LED de alta intensidade, duas resistências eléctricas montadas em série (uma fixa de $25 \mathrm{Ohm} \mathrm{e}$ outra variável de 0 a $350 \mathrm{Ohm}$ para a regulação da intensidade luminosa) e um interruptor de passagem de corrente (10 na Fig. 3). Todo este conjunto foi colocado numa pequena caixa metálica instalada ao longo da base do instrumento.

\section{3 - TÉCNICA EXPERIMENTAL}

Posiciona-se o porta amostras na plataforma circular e nivela-se o aparelho com o auxílio de um nível de bolha de ar, actuando nos parafusos das extermidades da base. Coloca-se uma gota do líquido a estudar no centro do substrato sólido com uma micropipeta e liga-se o sistema de iluminação. Através dos parafusos dos movimentos longitudinal e vertical, foca-se e posiciona-se a gota, tal que o plano focal (perpendicular ao plano do substrato sólido) passe pelo centro da gota. Com o parafuso do movimento transversal faz-se coincidir a imagem de uma das extermidades, direita ou esquerda, da gota com o centro dos dois retículos. Roda-se o retículo em cruz de modo a que um dos traços seja tangente à imagem da superfície da gota no ponto de contacto desta com o substrato sólido. Em seguida lê-se o ângulo formado entre a superfície do substrato sólido e a tangente, no retículo angular, no sentido do interior da gota para o seu exterior. Todas as medições são feitas, alternadamente, na extermidade direita e esquerda da gota, três vezes para cada par líquido/substrato.

\section{4 -SISTEMAS ESTUDADOS}

Já se referiu anteriormente o interesse das medidas de ângulos de contacto na avaliação da molhabilidade de um líquido relativamente a um substrato.

O goniómetro aqui descrito foi manuseado por diversos estudantes, na determinação do ângulo de contacto de alguns líquidos em diferentes substratos. Na tabela I mostram-se os ângulos de contacto para diferentes líquidos sobre teflon, lidos neste goniómetro e num goniómetro comercial (NRL contact angle goniometer, catalog n० 100-00) da Ramé-Hart.
Apresentam-se igualmente os valores da literatura, para comparação; no entanto, as medidas efectuadas em ambos os goniómetros não foram feitas em ambiente saturado, ao contrário dos valores da literatura.

Como se pode observar na tabela anterior, os valores obtidos e a reprodutibilidade dos resultados do goniómetro descrito, são comparáveis aos lidos no aparelho comercial. Foram ainda lidos os ângulos de contacto dos líquidos que figuram na Tabela I em substratos sólidos diferentes, nomeadamente poli (cloreto de vinilo) (PVC), aço inox, vidro e poli(tereftalato de etileno) (PET). De igual forma foram observados valores e reprodutibilidades comparáveis nos dois aparelhos.

\section{CONCLUSÕES}

Mostra-se neste trabalho que é possível a construção de um goniómetro de ângulos de contacto, que conduz a resultados comparáveis aos de um aparelho comercial, mas de custo significativamente inferior. Além disso, este modelo apresenta melhoramentos face ao aparelho comercial, resultando num modelo compacto $(18 \mathrm{~cm} \times 23 \mathrm{~cm} \times 28 \mathrm{~cm}$, cerca de metade das dimensões do aparelho comercial) e facilmente transportável, pesando menos de $2 \mathrm{~kg}$ sem o estojo de transporte, o

Tabela I - Comparação dos valores de ângulos de contacto sobre teflon, medidos no goniómetro aqui descrito, com os determinados no goniómetro comercial da Ramé-Hart e comparados com os valores da literatura

\begin{tabular}{cccc}
\hline Líquido & $\begin{array}{c}\text { Ângulo de contacto no } \\
\text { goniómetro descrito }\end{array}$ & $\begin{array}{c}\text { Ângulo de contacto no } \\
\text { goniómetro Ramé-Hart }\end{array}$ & $\begin{array}{c}\text { Valores } \\
\text { da Literatura }\end{array}$ \\
\hline Água destilada & $107 \pm 3$ & $100 \pm 5$ & $988,1087,17$, \\
Di-iodometano & $77 \pm 2$ & $77 \pm 3$ & $112^{9}, 118^{10}$ \\
n-octano & $20 \pm 2$ & $21 \pm 5$ & $8511,88^{12}$ \\
n-decano & $35 \pm 1$ & $39 \pm 7$ & 268,3013 \\
1-propanol & $33 \pm 1$ & $35 \pm 5$ & $4313,3514,4015$ \\
Glicerol & $100 \pm 3$ & $104 \pm 1$ & 10110 \\
\hline
\end{tabular}


$21 \times 28$

\section{Casa no campo, condomínio fechado, grande área I}
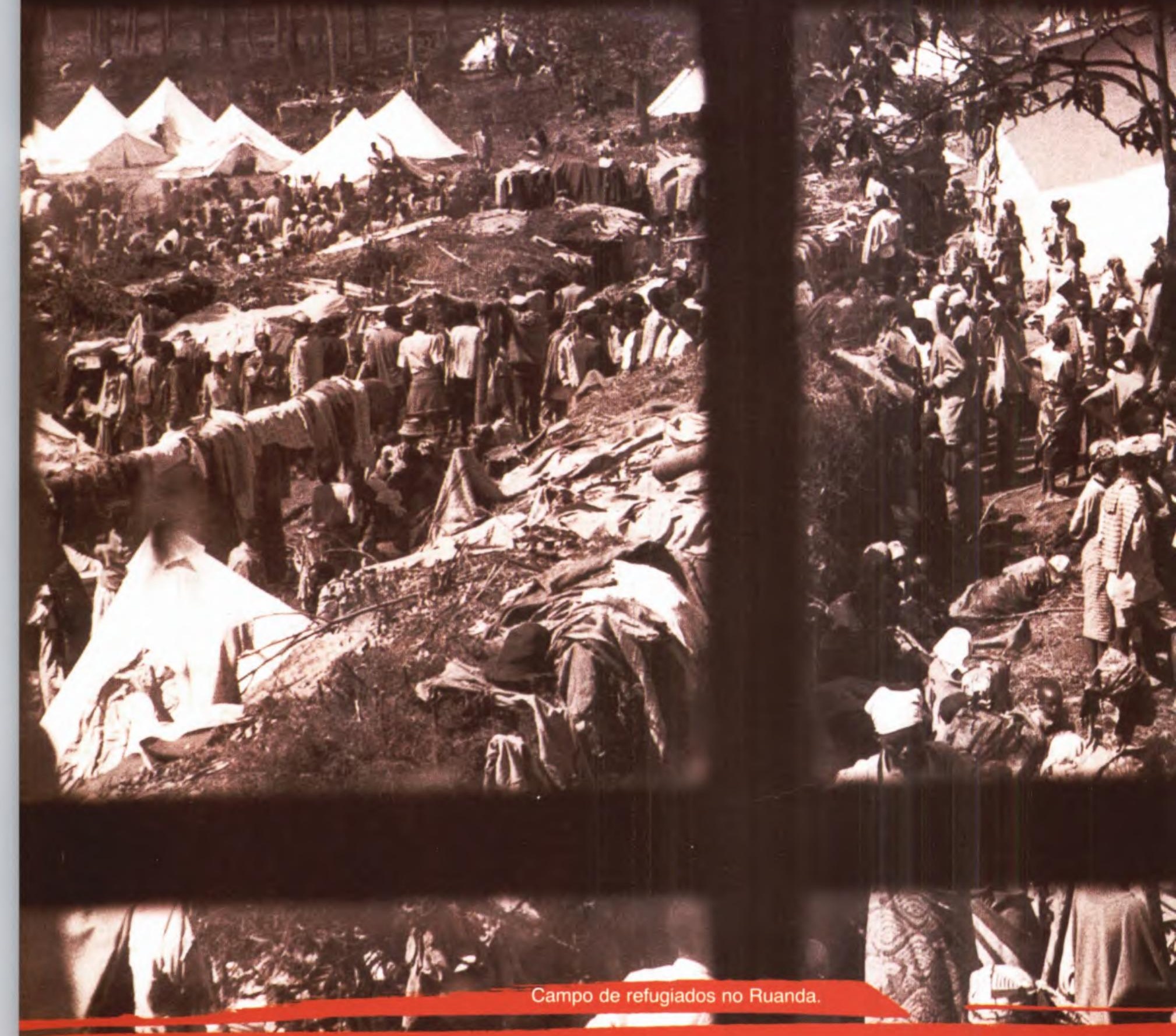
que, aliado ao facto de possuir fonte de iluminação própria e não depender da rede eléctrica, o torna muito mais prático do ponto de vista de utilização. Mais ainda, a imagem da gota é observada com a concavidade virada para cima e apresentando uma ampliação de 50X, o que facilita a medição do ângulo de contacto relativamente ao aparelho comercial, que apresenta uma imagem invertida e uma ampliação de apenas 23X.

Optou-se na construção, pela escolha de uma objectiva fixa, tal como no goniómetro comercial, ou seja, ausência de um sistema rotativo de objectivas (à semelhança do que acontece num microscópio clássico) para escolha da melhor ampliação da gota, o que simplificou a construção deste aparelho. Desta forma, a ampliação conseguida não é variável, o que representa uma limitação deste tipo de instrumentos.

Encontra-se neste momento em estudo a construção da câmara de saturação de vapor para o porta amostras, de modo a que os ângulos de contacto sejam medidos em condições de equilíbrio entre o líquido e o seu vapor. Para tal, uma caixa cúbica em acrílico $(40 \mathrm{~mm}$ de aresta) envolverá a plataforma de suporte do porta amostras, estando solidária com esta. A face superior do cubo funcionará como porta de acesso ao substrato sólido. Há ainda a hipótese de se adicionar à caixa uma resistência eléctrica ou simplesmente uma lâmpada, uma ventoínha eléctrica ou um sistema manual de agitação e um termopar ligado à resistência, de modo que seja possível variar a temperatura dentro da câmara de saturação de uma forma controlada.

Com os valores dos ângulos de contacto dos líquidos estudados sobre diversos substratos sólidos e as tensões superficiais dos líquidos puros, é possível através da equação de Young-Dupré (equação (3)) calcular os respectivos trabalhos de adesão líquido-sólido. Mais ainda, assumindo este trabalho como o dobro da média geométrica das tensões superficiais da interface sólido-vapor,
$\gamma_{S V}$, e da interface líquido-vapor, $\gamma_{\mathrm{LV}}{ }^{18}$, pode prever-se através da equação de Young e da equação (2) o valor de $\gamma_{\mathrm{Sv}}{ }^{19}$.

\section{AGRADECIMENTOS}

Os autores agradecem ao Prof. Manuel Maneira (Dep. Física da FCT-UNL) a cedência do goniómetro de ângulos de contacto da Ramé-Hart, e as proveitosas discussões, conselhos e esclarecimentos prestados pela Prof ${ }^{a}$ Benilde Saramago (CQE-UTL), Enga Natália Correia (CQFM - UTL), Prof. a Anabela Fernandes (CQE-UTL) e pelo Prof. Joaquim Moura Ramos (CQFM-UTL).

a) Departamento de Química, Faculdade de Ciências e Tecnologia, Universidade Nova de Lisboa

b) Planetário Calouste Gulbenkian

c) Estudante da licenciatura de Química Aplicada na FCT-UNL

\section{REFERÊNCIAS}

1. S. Baxter, A.B.D. Cassie, I. Text. Inst., 36, T67 (1945): A.B.D. Cassie, S, Baxter, Trans, Faraday Soc, 40, 546 (1944).

2. A. G. Gaonkar, R. D. Neuman, I. Colloid Interface Sci., 98 (1), 112 (1984); "Solution Behavior of Surfactants", vol.1, K.L. Mitlal e E.S. Fendler ed.s, Plenum Press, 1982.

3. A.P. Serro, A.C. Fernandes, B. Saramago, J. Lima M. A. Barbosa, Biomaterials, 18, 963 (1997); A.P. Serro, A.C. Fernandes, B. Saramago, Colloids and Surfaces A: Physiochem. Eng. Aspects, 125, 209, (1997).

4. M. E. Schrader, I. Colloid Interface Sci., 100(2), 372 (1984).

5. Arthur W. Adamsom, "Physical Chemistry of Surfaces", $5^{\text {th }}$ ed., Wiley \& Sons, New York, 1990, cap. X e referências nele contidas.

6. I. I. Moura Ramos, Langmuir, 13(24), 6607 (1997).

7. W. A. Zisman, Adv. Chem. Ser., 43, (1964).
8. P.Hu, A. W. Adamson, I. Colloid Interface Sci., 59 605 (1977).

9. I. R. Dann, J. Colloid Interface Sci, 32, 302 (1970).

10. C. I. Van Oss, R. I. Good, M. K. Chaudhury, Langmuir, 4, 884 (1988).

11. A. El-Shimi, E.D. Goddard, I. Colloid Interface Sci., 48, 242 (1974).

12. F. M. Fowkes, D.C. McCarthy, M. A. Mostafa, /. Colloid Interface Sci, 78, 200 (1980).

13. C. L. Sutula, R. Hautala, R.A. Dalla Betta, L. A. Michel, Abstarcts 153rd Meeting, American Chemical Society, April 1967

14. H. W. Fox, W. A. Zisman, I. Colloid Interface Sci., 5. 514 (1950).

15. A. W. Adamson, I. Colloid Interface Sci., 44, 273 (1973.

16. J. B. Jones, A. W. Adamson, J. Phys. Chem., 72, 646 (1968).

17. M. Yekta-Fard, A. B. Ponter, I. Colloid Interface Sci., 126 (1), 134, (1988).

18. N. T. Correia, I. I. Moura Ramos, Benilde I. V. Saramago, Jorge C. G. Calado, I. Colloid Interface Sci., 189, 361 (1997).

19. M. Dionísio, I. Sotomayor, artigo em preparação.

- Autor a quem deve ser endereçada a correspodência * A equação de Young descreve uma situação de equilíbrio para um sistema onde o sólido está em equilíbrio com o vapor do líquido. Este equilíbrio com o vapor é um requisito fundamental para que as medidas de ângulos de contacto sejam correctas e reprodutiveis e tenham significado termodinâmi$\operatorname{co}^{5,6}$.

... Em rigor, o trabalho de adesão nas equações (2) e (3) deveria ser escrito como $\mathrm{W}_{\mathrm{S}(\mathrm{V}) \mathrm{L}}{ }^{6}$. A diferença reside na definição da tensão superficial do sólido. Assim, $W_{\text {SL }}$ refere-se a $\gamma_{S}$, isto é, a tensão superficial do sólido no vácuo, e que difere de $\gamma_{\mathrm{Sv}}$ de uma quantidade $\pi_{\mathrm{e}}$, a pressão de espalhamento. É frequente encontrar-se na literatura apenas $W_{\mathrm{SL}}$. mesmo quando se trata de $W_{S(V) L}$, daí termos adoptado essa notação. 


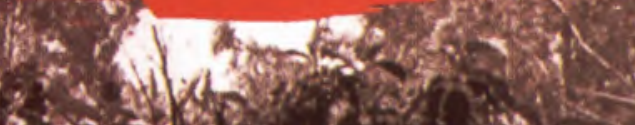



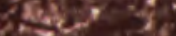

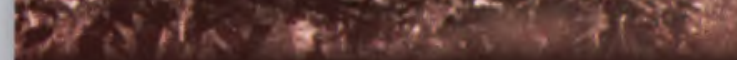

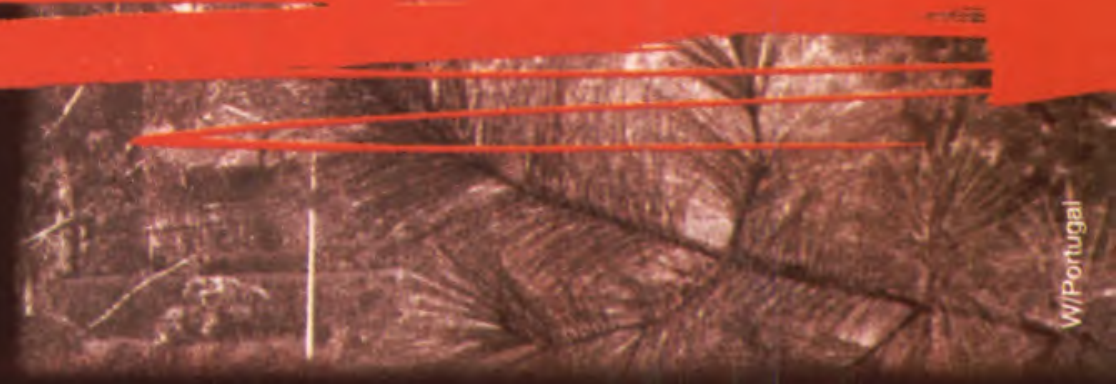

berta, segurança 24 horas por dia, pronta a habitar.
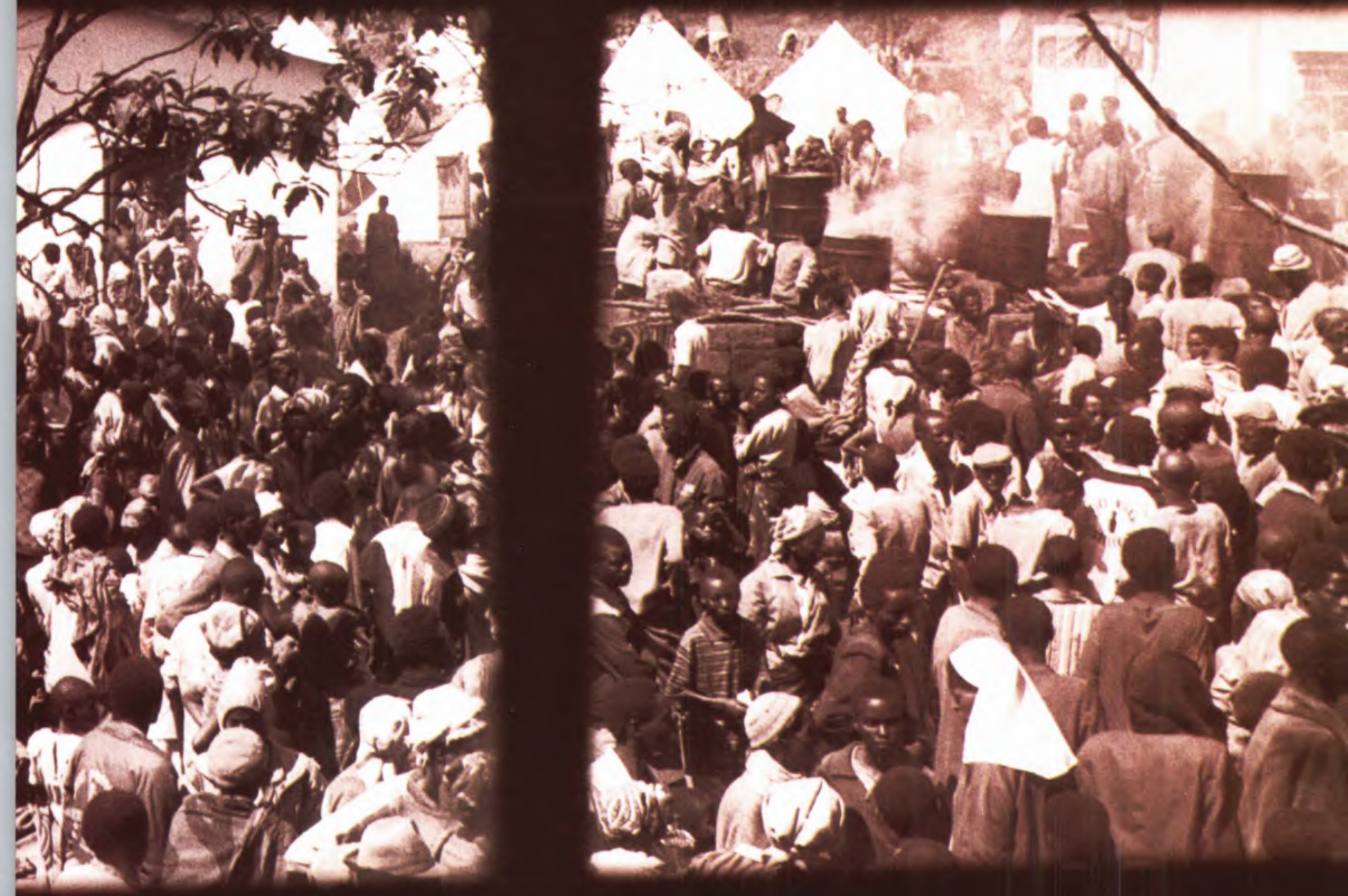

3

1) 1

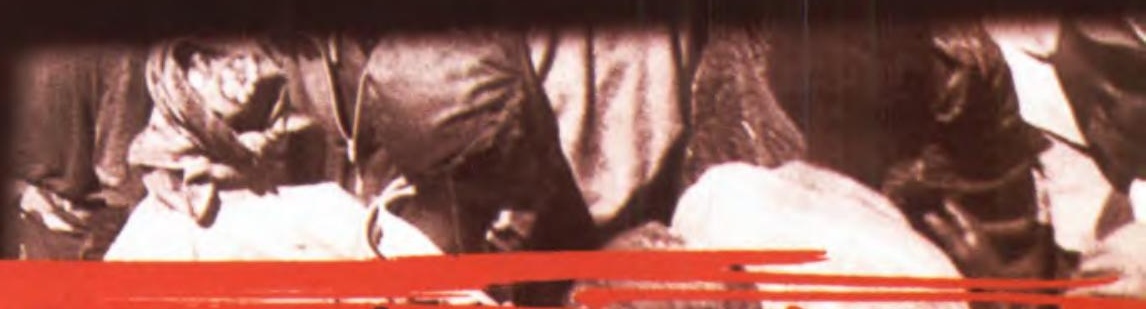

Amnistia Internacional. 